\title{
The Impact of Dealing Patterns on Purchase Behavior
}

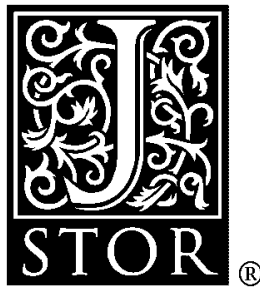

\author{
Aradhna Krishna
}

Marketing Science, Vol. 13, No. 4. (Autumn, 1994), pp. 351-373.

Stable URL:

http://links.jstor.org/sici?sici=0732-2399\%28199423\%2913\%3A4\%3C351\%3ATIODPO\%3E2.0.CO\%3B2-T

Marketing Science is currently published by INFORMS.

Your use of the JSTOR archive indicates your acceptance of JSTOR's Terms and Conditions of Use, available at

http://www.jstor.org/about/terms.html. JSTOR's Terms and Conditions of Use provides, in part, that unless you have obtained prior permission, you may not download an entire issue of a journal or multiple copies of articles, and you may use content in the JSTOR archive only for your personal, non-commercial use.

Please contact the publisher regarding any further use of this work. Publisher contact information may be obtained at http://www.jstor.org/journals/informs.html.

Each copy of any part of a JSTOR transmission must contain the same copyright notice that appears on the screen or printed page of such transmission.

The JSTOR Archive is a trusted digital repository providing for long-term preservation and access to leading academic journals and scholarly literature from around the world. The Archive is supported by libraries, scholarly societies, publishers, and foundations. It is an initiative of JSTOR, a not-for-profit organization with a mission to help the scholarly community take advantage of advances in technology. For more information regarding JSTOR, please contact support@jstor.org. 


\title{
THE IMPACT OF DEALING PATTERNS ON PURCHASE BEHAVIOR
}

\author{
ARADHNA KRISHNA \\ Columbia University
}

\begin{abstract}
We explore the effect of dealing patterns on consumer purchase behavior by developing a normative purchase quantity model that can incorporate any dealing pattern. The model adds to the stream of research on optimal purchasing policy by demonstrating how dealing patterns can be incorporated in a simple manner in dynamic programming models. Implications for purchase behavior are derived by employing the model in a numerical simulation in which time between deals is characterized by a Weibull distribution. The flexibility of the Weibull distribution enables us to establish how particular facets of the dealing distribution (e.g., certainty in deal timing, minimum time between deals ) affect consumer behavior with respect to optimal purchase quantity, inventory, etc. One of the implications of the model is that the average quantity purchased on deal should be larger when there is greater certainty in deal timing. The model also shows that the average quantity purchased on deal should be larger when deals are spaced further apart, even though the buyer is presented with the same number of deals. We test certain model implications in a laboratory experiment and find actual behavior varying across dealing patterns in a manner consistent with model implications.

(Promotions; Buyer Behavior; Price Expectations; Inventory Models; Decision Making Under Uncertainty)
\end{abstract}

\section{Introduction}

Consider the following scenarios: (i) a deal occurs every fourth week, (ii) deals occur with equal likelihood every three, four, or five weeks, (iii) there is a $25 \%$ chance of a deal in any week. Deal frequency is the same in these three scenarios, but deal pattern varies. Does deal pattern influence purchase behavior? That is the question we ask here.

Dealing patterns observed for various brand-sizes observed in a New York supermarket vary greatly, as can be seen in Figure 1. Coca-Cola and Pepsi are promoted on alternate weeks, Palmolive dishwashing detergent and Crest toothpaste every 3-6 weeks. Tropicana orange juice appears to be promoted in an arbitrary fashion. ${ }^{1}$

That dealing patterns might influence purchase behavior has been suggested by a number of marketing researchers (Krishna 1991, p. 450; Winer 1986, p. 255). However, there exists little research on the subject. We propose a purchase quantity model that incorporates the impact of dealing patterns. Because it can take into account any distribution of time between deals, the model can provide the optimal purchase quantity for

\footnotetext{
${ }^{1}$ We cannot do statistical tests for randomness in this limited dataset. We only state here the impression the data may give to a buyer observing these dealing patterns.
} 


\begin{tabular}{llllllllllllllll}
$\mathrm{D}$ & $\mathrm{D}$ & $\mathrm{D}$ & & $\mathrm{D}$ & $\mathrm{D}$ & $\mathrm{D}$ & $\mathrm{D}$ & $\mathrm{D}$ & $\mathrm{D}$ & $\mathrm{D}$ \\
\hline & $\mathrm{D}$ & $\mathrm{D}$ & $\mathrm{D}$ & $\mathrm{D}$ & $\mathrm{D}$ & $\mathrm{D}$ & $\mathrm{D}$ & $\mathrm{D}$ & $\mathrm{D}$ & $\mathrm{D}$ \\
\hline $\mathrm{D}$ & & & $\mathrm{D}$ & & & $\mathrm{D}$ & & & & $\mathrm{D}$ & & $\mathrm{D}$ \\
& & & & & & & & & & & & & $\mathrm{D}$ \\
\hline
\end{tabular}

\begin{tabular}{lllll}
\hline $\mathrm{D}$ & $\mathrm{D}$ & $\mathrm{D}$ & $\mathrm{D}$ \\
\hline
\end{tabular}

Coke (2 liters)

Pepsi (2 liters)

Palmolive dishwashing detergent (22 oz.)

Charmin bathroom tissue (6 roll)

\begin{tabular}{llll}
\hline $\mathrm{D}$ & $\mathrm{D}$ & $\mathrm{D}$ & $\mathrm{D}$ \\
\hline
\end{tabular}

D

D

D

D

D
D

D
D

D
Crest toothpaste $(4.6 \mathrm{oz}$.

Dolly Madison ice cream (1/2 gallon)

Sealtest ice cream ( $1 / 2$ gallon)

Bounty paper towels (1 roll)

7-Up (2 liters)

Tropicana ( $1 / 2$ gallon)

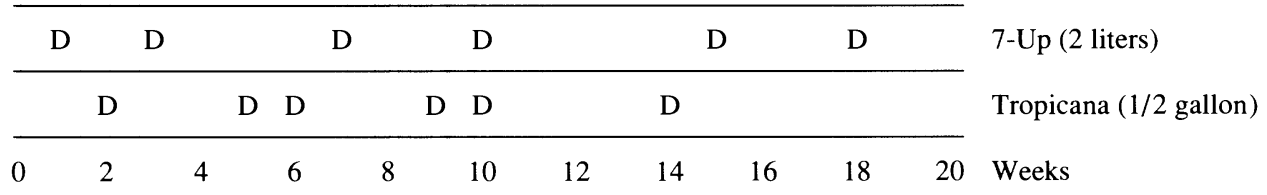

D denotes a deal.

FigurE 1. Dealing Patterns Observed in the Supermarket.

any dealing pattern. We employ the model to explore the effect of dealing patterns on various aspects of consumer purchase behavior, for example, quantity purchased on deal, holding cost, and average cost.

The model fits into a stream of recent marketing research that builds rational models of purchasing under price uncertainty. The starting point for much of this research is Golabi's (1985) zero-order model (prices in each time period are independent of prices in prior periods) for the case of a single good and constant consumption rate. Golabi's model is extended by Krishna (1992) to the multiple brand case (allowing for brand loyalty), and by Assuncao and Meyer (1993) to accommodate variable consumption rate and first-order dealing patterns (where the price in one time period may hold information about the price in the next period). The proposed model further extends this research to incorporate the effect of any dealing pattern.

Assuncao and Meyer (1993) investigate the effect of dealing patterns on purchase behavior in the simple context of a first-order dealing pattern. They find that the lower the probability of consecutive discounts (i.e., discounts in consecutive periods), the higher the optimal purchase quantity on discount. First-order models contain information about the probability of a deal in the next period, conditional on whether a deal has/has not occurred in the current period (i.e., first-order correlation among deal probabilities). However, they do not contain any information about the probability of a deal beyond the next period (higher-order correlations). Thus, they cannot incorporate the phenomenon that retailers may wish to wait at least two or more weeks between promotions of a particular item. The only way in which a first-order model can try and represent this effect is to decrease the probability of a deal in consecutive periods, thereby cutting down the overall deal frequency, and hence not representing the dealing pattern appropriately.

Further, since first-order models cannot accommodate different probabilities of deal occurrence in different weeks from the last deal (e.g., different probability of a deal in week $t$ versus week $t+1$ from the last deal), they cannot represent the phenomenon 
that the longer the time for which a deal has not occurred, the higher may be the probability of a deal occurrence in the next period. Also, they cannot distinguish between two dealing patterns where the probability of a deal in weeks $t, t+1, t+2, \ldots$, from the last deal is different, while the overall deal frequency is the same. Hence, for example, first-order models will predict the same purchase behavior for two consumers facing different dealing patterns where in one pattern a deal occurs regularly every three weeks, whereas in the other, a deal occurs with equal chance every two, three, or four weeks. However, the two consumers should (and we demonstrate that they do) behave quite differently. Firstorder models would try and represent both the patterns by adjusting the probability of deals in consecutive periods and not represent either pattern appropriately.

In addition, dealing patterns with gaps of more than two weeks are quite realistic (see Figure 1 where this is true for most brand sizes). McCann, Tadlaoui and Gallagher (1990) observed: "The firm pays attention to the last time it promoted the item." Reluctance to offer the same item on deal in consecutive weeks has also been demonstrated by Curhan and Kopp (1986). More realistic dealing patterns will thus have the same (zero) probability of dealing for a few weeks after a deal occurrence, and then have different probabilities of deal occurrence in periods thereafter (i.e., different probabilities of deal occurrence in weeks $t, t+1, t+2, \ldots$, from the last deal). These patterns cannot be captured by first-order models. However, they can be captured by higher-order models.

Thus, while Assuncao and Meyer's work is interesting, it needs to be extended to incorporate the other, more realistic, dealing patterns where there may be gaps of two weeks or longer between deals, and where deal probabilities may differ in different periods beyond the last deal, e.g., most of the patterns in Figure 1. A number of important questions revolve around these more likely dealing patterns. For example, if dealing pattern $A$ ensures greater certainty about when a deal will occur versus dealing pattern $B$, should the consumer buy a larger quantity on deal if he faces pattern $A$ or $B$ ? The same question might be asked for two dealing patterns that have different minimum time between deals (but have the same deal frequency).

The model proposed in this paper being $k^{\text {th }}$-order (i.e., prices in the last $k$ periods may hold information about price in the current period), can incorporate higher-order $\left(k^{\text {th }}\right.$. order) correlations between deal probabilities and thus accommodate more realistic dealing patterns. The model provides a normative basis for exploring optimal purchase policy under different dealing patterns. Implications for purchase behavior are derived by employing the model in a numerical simulation in which time between deals is characterized by a Weibull distribution. The flexibility of the Weibull distribution enables us to establish how particular facets of the dealing distribution (e.g., certainty in deal timing, minimum time between deals) affect consumer behavior with respect to optimal purchase quantity, inventory, etc.

One might also ask whether consumers will act as the normative model predicts. If consumer behavior is not consistent with the normative model, what are differences between actual and predicted behavior, and do they hold across consumers? It has been suggested that rational purchase policy models may give a good first approximation of the effect of a seller's temporal pricing policy on consumer purchase behavior (Helsen and Schmittlein 1992, Krishna 1992, Meyer and Assuncao 1990), but tests of normative models are rare in the literature (Meyer 1991). The present research tests through a laboratory experiment whether consumer behavior varies across different dealing patterns and how closely it corresponds to model predictions.

The primary contribution of this paper is a framework for understanding the impact of dealing patterns on purchase behavior. Beyond that, we substantiate the model in a laboratory experiment that allows us to study differences in purchase behavior associated with differences in dealing patterns. Finally, our model structure can incorporate any dealing pattern very simply into dynamic programming models, rendering it useful for 
such other applications involving dealing patterns as, for example, building a retailer ordering and pricing model.

It is important to note that this paper concentrates on optimal policy for the buyer, given a specific dealing pattern. We do not consider the market forces responsible for different dealing patterns in the market, nor whether these dealing patterns are optimal for the seller. The remainder of the discussion is organized as follows. In $\S 2$, we build the model and illustrate how it can be used to derive optimal purchase quantity for a specific dealing pattern. We apply the model to a Weibull distribution and numerically generate model implications in $\S 3$. In $\$ 4$, we test these implications in a laboratory experiment.

\section{Modeling Optimal Purchase Policy for a General Interdeal Time Distribution}

The model derived in this section determines optimal purchase quantity for a buyer on a specific purchase occasion, given the buyer's expectations of dealing patterns. Consumers are assumed to have accurate expectations of the dealing pattern. This is consistent with research that has shown that some consumers have reasonably accurate knowledge about deals (Dickson and Sawyer 1990, Krishna, Currim and Shoemaker 1991, Le Boutillier, Le Boutillier and Neslin 1994), and in line with previous research in this stream (e.g., Assuncao and Meyer 1993, Helsen and Schmittlein 1992, Krishna 1992). ${ }^{2}$ For simplicity, we build the model for the case of a single good (as in commodity markets or with strict brand loyalty).

\subsection{Assumptions}

Our assumptions are similar to those made by earlier models in this stream of literature (Assuncao and Meyer 1993, Krishna 1992, Golabi 1985). We assume the buyer visits the store during every period (e.g., every week), consistent with the observed shopping behavior of many individuals (Kahn and Schmittlein 1989). For simplicity, we assume the price distribution to be binary, that is, the product is available either at a sale price or a regular price. This may be observed for many brands. We further assume the interdeal time distribution to be stationary, that is, the probability distribution of the time to the next deal is the same, after each deal.

The buyer's per period rate of consumption of the good is assumed to be a constant, $c$. Consumption rate is assumed to be an integer multiple of available package-sizes. Finally, we assume holding cost to be a linear function of inventory $z$, with non-negative coefficient $h$, and there to be no backlogging of demand and no stockouts.

\subsection{Notation}

Let

$R=$ regular price for one unit of the product,

$S=$ sale price for one unit of the product,

$D=$ discount for the product when it is on sale, i.e., $R-S$,

$c=$ consumption per period in units,

$h=$ buyer's holding cost per period for one unit of the product,

$z=$ inventory of the product at the beginning of a given period,

$y=$ product quantity purchased (in units),

$\alpha=$ rate of discount per period (for cost),

$p_{i}=$ probability that the next deal will occur in the $i$ th period from the previous deal,

\footnotetext{
${ }^{2}$ Strictly speaking, the model itself makes no assumption about the accuracy of buyer expectations. However, when we use the model in a simulation to generate implications, then we assume that buyer expectations of deals are consistent with the actual occurrence of deals. Thus, in the simulation, consumers have accurate expectations.
} 
$q_{i}=$ probability that a deal will not occur until the end of the $i$ th period from the previous deal $=1-\sum_{j=1}^{i} p_{j}$, so that $q_{1}=1-p_{1}, q_{2}=1-p_{1}-p_{2}, \ldots$, and

$p_{0}=0, q_{1}=1, \operatorname{Lim}_{N \rightarrow \infty} q_{N} \rightarrow 0$.

Note that $p_{i}$ and $q_{i}$ define the dealing pattern.

Let $V_{m}(\alpha, z)$ be the expected total cost of purchasing and holding the good, from the beginning of period $m$ until an infinite horizon, given a discount rate of $\alpha$ and starting inventory $z . V_{m}(\alpha, z)$ is measured at the time at which a deal occurs. ${ }^{3}$ For purposes of exposition we assume purchases to be made at the beginning of each period and there to be no holding cost for consumption within the period.

\subsection{Buyer's Problem}

The buyer's task is to decide whether to make a purchase on a shopping trip, and how many units to purchase so as to minimize expected total cost of purchasing and holding, $V_{m}(\alpha, z)$. Minimizing the expected total cost equation yields optimal purchase quantity. Lemma 1 aids in the development of the equation by restricting the domain of purchase quantity.

LEMMA 1. The optimum policy is to buy up to $K$ periods on deal for some $K \geq 0$.

This lemma states that the buyer should purchase on deal sufficient units of the good to last for $K$ 'full' periods (and not to last till a fraction of a period) (proof in Appendix A.1).

Expected Total Cost Equation: Total cost may be denoted by the standard Bellman's optimality equation (1957):

$$
\begin{aligned}
V_{m}(\alpha, z)= & {[S(K c-z)+h c(K-1)]+\alpha\left[q_{1}(K-2) h c+p_{1} V_{m+1}(\alpha, K c-c)\right] } \\
& +\alpha^{2}\left[q_{2}(K-3) h c+p_{2} V_{m+2}(\alpha, K c-2 c)\right]+\cdots \\
& +\alpha^{K}\left[q_{K} R c+p_{K} V_{m+K}(\alpha, 0)\right]+\alpha^{K+1}\left[q_{K+1} R c+p_{K+1} V_{m+K+1}(\alpha, 0)\right] \\
& +\cdots
\end{aligned}
$$

$V_{m}(\alpha, z)$ comprises the cost for the current period and expected cost of future periods. The cost for each period includes purchasing and holding costs. Presented with a deal, the buyer purchases a sufficient quantity so that his inventory lasts for $K$ periods (i.e., he purchases to bring his inventory to $K c$ units). Given $z$ units in stock, the buyer purchases $K c-z$ units. Current period consumption is $c$ units, with $K c-c$ units carried to the next period.

By definition, $V_{m}(\alpha, z)$ is measured at the time a deal occurs. The first term thus denotes the cost of purchasing on deal $K c-z$ units at price $S$ in the current period $m$, and of holding $c(K-1)$ units of inventory until the next period, $m+1$. The second term denotes the discounted expected cost for period $m+1$, in which the probability of a deal occurring is $p_{1}$. If a deal does occur in this period, the buyer's expected future cost is denoted by $V_{m+1}(\alpha, K c-c)$. If a deal does not occur, the buyer incurs a holding cost of $q_{1}(K-2) h c$ until the next period, $m+2$. The third term is for period $m+2$, and so on. If a deal does not occur in the next $K$ periods, the consumer must begin to purchase off-deal at price, $R$, for current consumption in period $m+K$. The discounted cost for the current period in period $m+K$ is thus $\alpha^{K} R c$, the discounted expected cost of future periods $\alpha^{K} V_{m+K}(\alpha, 0)$.

\footnotetext{
${ }^{3} V_{m}(\alpha, z)$ is defined only for stationary points in time. Deal points are stationary in that the probability of the next deal is measured from the occurrence of the last deal. This is merely notation used to set up the problem in a mathematically tractable way; it in no way detracts from the generalizability of the model.
} 


\subsection{Optimal Purchase Quantity}

We prove in Appendix A.2 that optimal quantity is an amount that brings inventory up to $K$ periods of consumption, where $K$ satisfies the following two inequalities:

$$
\begin{gathered}
D q_{K} \leq \sum_{i=0}^{K-1} q_{i} h, \quad \text { and } \\
D q_{K-1} \geq \sum_{i=0}^{K-2} q_{i} h .
\end{gathered}
$$

Purchase cost is reduced by purchasing on deal, but purchasing an extra quantity on deal incurs an additional holding cost. Intuitively, the left-hand-side (LHS) of the equations shows the expected opportunity cost (i.e., deal savings) of not purchasing on the deal, the right-hand-side (RHS) the expected extra cost (i.e., holding cost) if the buyer were to purchase on deal. Holding cost (RHS) increases quadratically, deal savings (LHS) linearly, with quantity purchased. The optimal number of periods to buy until $(K)$ is such that expected deal savings are just greater than or equal to expected holding cost. This ensures the buyer the greatest expected net deal savings (deal savings less holding cost ).

Equations (2) and (3) satisfy properties that we would expect to hold. For example, optimal purchase quantity is a nondecreasing function of deal amount and non-increasing function of holding cost. The equations form the basis for determining optimal purchase quantity for different dealing patterns. Henceforth, we call $K$ the "optimal number of stock-up periods" and $K c$ the "optimal stock-up quantity." The following propositions also hold from equations (2) and (3).

\subsection{Model Propositions}

PROPOSITION 1. The probability of deals beyond the optimal number of stock-up periods $(K)$ does not affect the value of $K$.

Proof. Analysis of equations (2) and ( 3 ) reveals that $K$ is dependent on $p_{i}$ only for $i \leq K$ and is independent of $p_{i}>K$.

PROPOSITION 2. The probability of a deal in earlier periods (from the last deal) has a greater impact on the optimal number of stock-up periods $(K)$ than the probability of a deal in later periods.

Proof. Equation (2) is a function of $\sum_{i=0}^{K-1} q_{i}$. Since $q_{i}=1-\sum_{j=1}^{i} p_{j}, p_{b}$ is used $K$ $-b$ times in the computation of $\sum_{i=0}^{K-1} q_{i}$, for all $i \leq b \leq K-1$. Thus, the smaller the $b$, the more times it is used in the computation. A similar argument applies to equation (3), which, together with equation (2), determines the value of $K$. Because inventory is consumed over time, more inventory is held in earlier periods than in later periods following a deal.

Note that this result is not dependent on the discounting of future deals.

Proposition 3. The optimal number of stock-up periods $(K)$ is a nondecreasing function of the ratio of discount to holding cost (i.e., $h$ versus $D$ ).

PROOF. This intuitively appealing proposition is obvious from equations (2) and (3).

\subsection{Determining Optimal Purchase Quantity for a Specific Dealing Pattern}

The optimal policy for any dealing pattern is to determine the optimal number of stock-up periods $(K)$ to satisfy equations ( 2$)$ and (3), by substituting the deal probabilities for the different patterns in these equations. Closed-form solutions for $K$ are easily obtained 
for some distributions, but for others computation of $\sum_{i=0}^{K-1} q_{i}$ (needed to compute $K$ ) may be too cumbersome. In this case, one can numerically determine the optimal purchase quantity.

\section{A Model-based Simulation of Buyer Purchase Behavior}

\subsection{Overview}

We used the model in a numerical simulation that employs a Weibull distribution of time between deals to derive implications regarding purchase behavior. The reason to use a Weibull distribution is its flexibility, which enables us to evaluate how purchasing behavior should vary with changes in different aspects of the dealing distribution. The Weibull is a three-parameter distribution. We term the three parameters of the Weibull distribution the shape parameter $(g)$, rate parameter $(\lambda)$, and delay parameter $(w)$ :

$$
F(x)=1-\exp \left[-(\lambda(x-w))^{g}\right] .
$$

Our model being discrete, we use a discretized version of the distribution to numerically derive the optimal number of stock-up periods $(K)$ for different values of the Weibull parameters. (Appendix A.3. explains how this is done.) $K$ is then used in a simulation that tracks changes in the values of certain aspects of purchase behavior (e.g., average quantity purchased on deal, average inventory) with variations in the mean of the Weibull distribution, shape, rate, and delay parameters.

All three Weibull parameters are meaningful to us. The shape parameter $(g)$ describes the shape of the distribution. A Weibull with $g=1$ describes an exponential distribution, where the probability of a deal occurring in the next period is independent of the occurrence of deals in prior periods. In a Weibull with $g=\infty$, the next deal can be predicted deterministically depending on when the last deal occurred. In general, the larger the $g$, the more peaked the distribution, and the greater the certainty as to when the next deal will occur. The rate parameter $(\lambda)$ defines the rate at which deals occur; it is the principal determinant of the distribution mean and, thus (together with the delay parameter ${ }^{4}$ ) of deal frequency. ${ }^{5}$ The delay parameter $(w)$ denotes the minimum time between two consecutive deals. If $w=0$, deals can occur in consecutive periods (henceforth, for simplicity, we assume that a week denotes a period); if $w=n$, at least $n$ weeks will separate two deals.

The flexibility of the Weibull distribution is evidenced by its ability to approximate very different dealing distributions by choosing appropriate values for the three Weibull parameters. For instance, if the shape parameter $g=999$, the rate parameter $\lambda=0.5$, and the delay parameter $w=0$, it can approximate the dealing patterns for Coke and Pepsi in Figure 1. Similarly, if $g=2, \lambda=0.33$, and $w=3$, it can approximate the dealing pattern for Sealtest ice cream.

\subsection{Simulation Description}

We simulated a period of two years. Deals were of one week duration (as is common in practice). For simplicity, consumption rate " $c$ " was assumed to be 1 unit per week. ${ }^{6}$ To ensure robustness of model implications values for model parameters were varied widely. $D / h$ was varied between 0.3 and $0.9(0.3,0.5,0.7,0.9),{ }^{7} g$ between 1 and 999 $(1,2,5,10,25,999), \lambda$ between 0.04 and $0.5(0.04,0.067,0.1,0.125,0.17,0.2,0.25$,

\footnotetext{
${ }^{4}$ If delay $=0$, then deal frequency $=($ number of weeks $) /(1 / \lambda)$; if delay $=x$, then deal frequency $=($ number of weeks $) /(x+(1 / \lambda))$.

${ }^{5}$ Number of weeks in which a deal occurs within a constant time interval.

${ }^{6}$ If $c$ changes, quantities purchased will change in the same proportion for any dealing patterns that we compare.

${ }^{7}$ Off-deal price does not matter for our implication, but $=1.0$.
} 
$0.33,0.5)$, and $w$ between 0 and $3(0,1,2,3)$. Figures 2 and 3 plot results of simulations run with parameter values chosen to illustrate:

- A very peaked distribution ( $g=999$ ), in which the timing is relatively certain. Since deals occur at more or less regular intervals (i.e., nearly every $n$ weeks), for brevity in exposition, we call this "Regular" distribution.

- A table-like or relatively flat distribution $(g=2)$ that reflects an approximately equal probability of a deal occurring within a specified time from the previous deal (e.g., a nearly equal chance of a deal occurring every $n-1, n, n+1$ weeks from the last deal) and nearly zero probability of a deal occurring otherwise, hereafter referred to as "Uniform" distribution.

- A geometric distribution, or the discrete counterpart of the exponential distribution $(g=1)$, in which a deal might occur with equal chance in any week without regard to when the last deal occurred, called a "Geometric" distribution.

Figure 2 plots two versions of these three distributions. In the version that sets delay $=0$, deals may occur in consecutive weeks; in the other, at least one week must elapse between deals. Figure 2 also varies dealing rate for all these distributions. Thus, Figure 2 illustrates different combinations of the three Weibull parameters. Both Figures 2 and 3 set $h=0.1$ and $D=0.5$.

\subsection{Implications}

Our simulation yields implications concerning certainty in deal timing, frequency, and delay (i.e., minimum time between deals). These are obtained by varying different parameters of the Weibull distribution, namely, shape, mean, delay and rate. Each implication is discussed in turn.
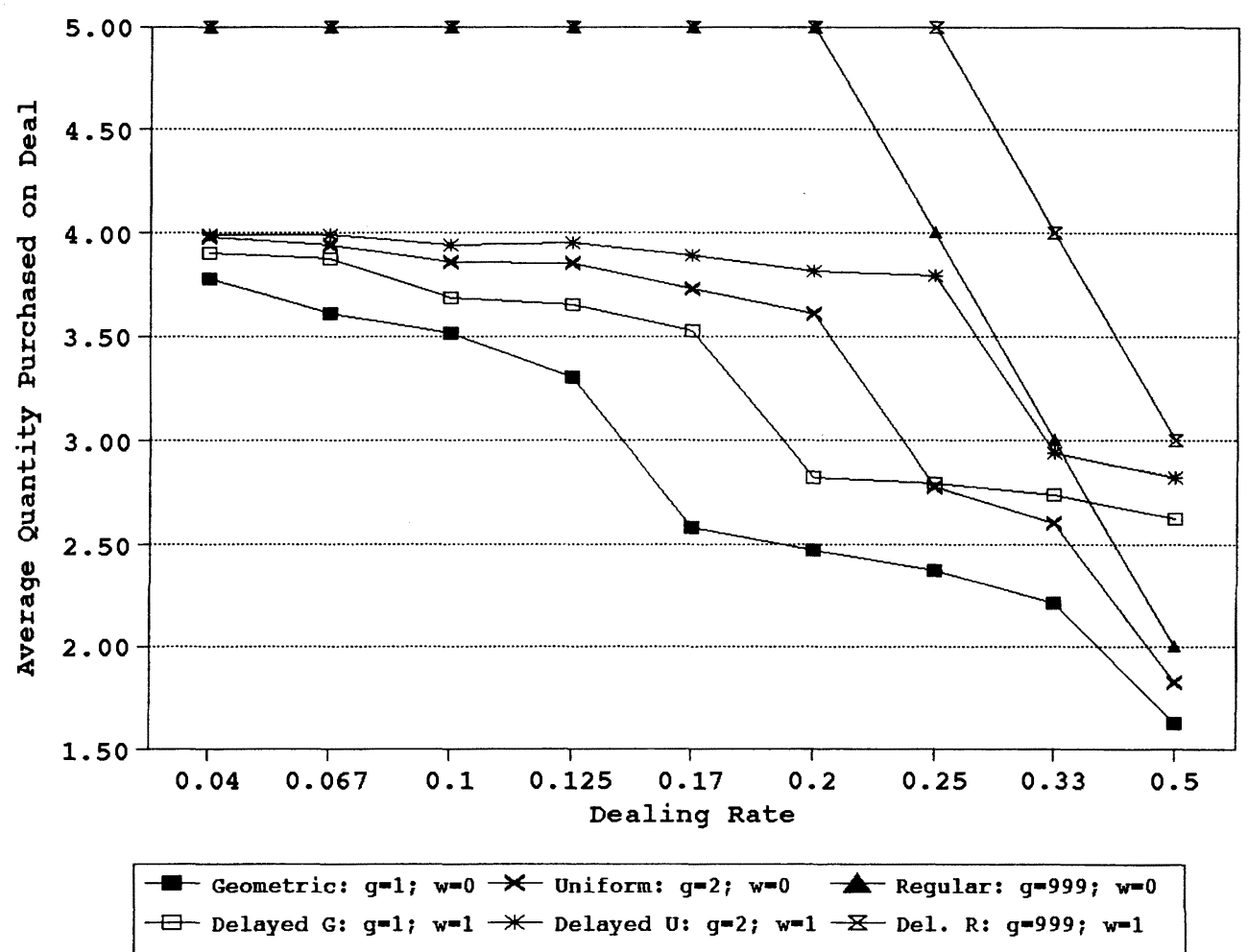

Figure 2. Effect of Shape, Rate, and Delay on Average Quantity Purchased on Deal. 


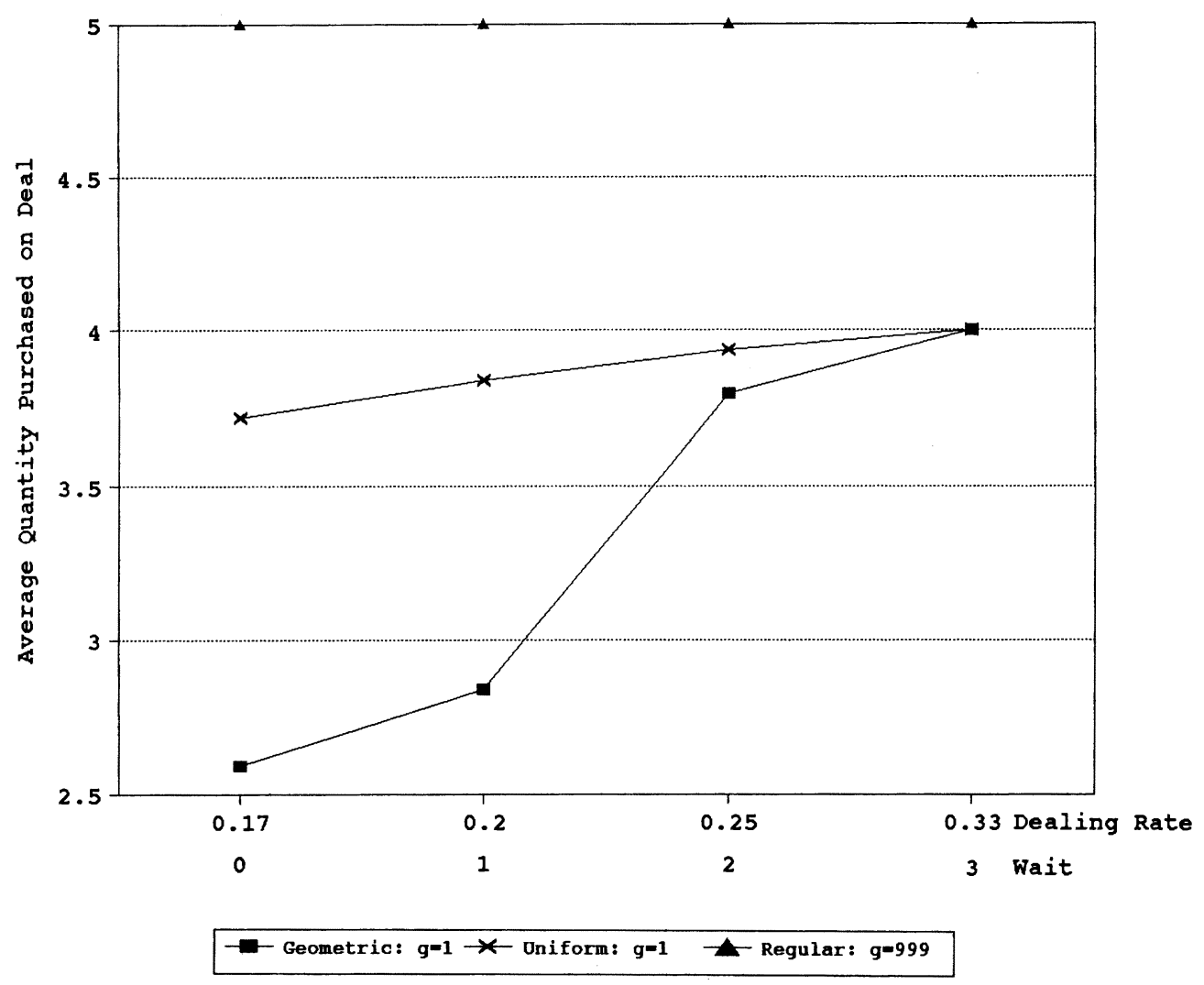

Figure 3. Effect of Delay (Same Mean) on Average Quantity Purchased.

3.3.1. Certainty in deal timing. The shape parameter affects certainty in deal timing. The larger the shape parameter, $g$, the more peaked the distribution and smaller the time interval in which the deal can occur. The result is greater certainty about deal timing.

IMPLICATION 1. The greater the certainty of when the next deal will occur (given constant deal frequency and delay), (i) the smaller the probability of overstocking ( having a positive inventory when the next deal occurs), ${ }^{8}$ (ii) the larger the average quantity purchased on deal, (iii) the larger the proportion of quantity purchased on deal, and (iv) the smaller the buyer's average cost of purchasing and holding inventory.

These results are independent of the value of the delay parameter. We now provide an intuitive explanation for why the implication holds.

(i) Probability of overstocking. Greater certainty of deal timing reduces the probability of overstocking. In fact, when $g=999$ and deals occur quite regularly, the probability of overstocking is zero.

(ii) Average purchase quantity on deal. The implication states that the average quantity purchased on deal should increase with greater certainty of when the next deal will occur (i.e., with greater peakedness in the distribution). This is counter-intuitive; one would expect buyers less sure about deal timing to purchase larger quantities on deal. Compare the finding that consumers purchase larger quantities on deal when the distribution is more rather than less peaked (compare geometric, uniform and regular patterns in Figure 2).

\footnotetext{
${ }^{8}$ Strictly speaking, implication (i) should read "the smaller (or same). . .". (or same) is excluded for brevity of text. The same is true for the other implications.
} 
Why does this implication hold? Average quantity purchased on deal should be determined by optimal stock-up quantity, $K c$, and the consumer's inventory at the time of the deal. Consider first the latter. According to Implication 1(i), when the dealing distribution is more peaked, consumers are likely to have little inventory on hand when a deal occurs and thus be in a position to purchase close to the optimal stock-up quantity on deal. When the distribution is less peaked, consumers may overstock and be holding a positive inventory when a deal occurs. Average purchase quantity on deals is consequently smaller than optimal stock-up quantity (by the extent of inventory) for less peaked distributions.

Now let's consider optimal stock-up quantity itself $(K c)$. Deals expected earlier have a greater effect on optimal stock-up quantity (decreasing it) than deals expected later do (increasing it; see proposition 2). Because deals are expected over a wider range of time for less peaked distributions, they can occur much earlier and much later from the previous deal for these distributions. The net effect of earlier (versus later) deals is thus stronger, reducing the optimal stock-up quantity for these distributions. Hence, optimal stock-up quantity is higher, and probability of overstocking is lower for more peaked distributions. Both decrease purchase quantity, resulting in a greater purchase quantity on deal for more peaked distributions. ${ }^{9}$ This result holds for any value of delay as illustrated in Figure 2, which compares Regular, Uniform and Geometric distributions for delay $=0$ and delay $=1$.

Figure 2 also demonstrates the importance of incorporating higher-order correlations in purchase quantity models. When delay $=1$, all three distributions ( Regular, Uniform and Geometric) have the same first-order correlation $(=0)$, but different higher-order correlations. First-order models, by definition, do not capture higher-order correlations, and, hence, cannot distinguish among these distributions. Such models would misleadingly predict the same purchase behavior for all three distributions, whereas Figure 2 plots distinctly different purchase quantities for the three delayed distributions.

(iii) Proportion of quantity purchased on deal. Implication 1 (ii) states that average purchase quantity on deal should be largest for more peaked distributions. The model also suggests that consumers should purchase on the same number of deals for any dealing pattern, it being optimal to purchase on every deal irrespective of dealing pattern and deal frequency being constant across dealing patterns. Together, this implies that the proportion of quantity purchased on deal should be higher when the distribution is more peaked.

Although it might seem reasonable for consumers to buy large amounts on deal when deals are uncertain, rendering the proportion purchased on deal the same across dealing patterns, optimal purchase policy dictates that consumers not buy large quantities on deal to avoid enormous holding costs.

(iv) Average cost (of purchasing plus holding). Our simulation shows holding cost to be generally higher for more peaked distributions. It may seem contrary that more peaked distributions have lower probability of overstocking but also have higher holding cost. This occurs because while there often is overstocking in the case of less peaked distributions, there are also more purchases made off-deal. Thus, consumers do not carry inventory for as much of the time as more peaked distributions, resulting in lower holding costs.

The simulation also suggests that more peaked distributions always have lower average costs whether or not they have higher holding costs. This is less puzzling when one

\footnotetext{
${ }^{9}$ If $D / h$ is much larger than the average time between deals, $K$ need not be highest for the most peaked distribution. Here, $K$ will equal the time between deals for the more peaked distributions. However, it may be higher for less peaked distributions because of the large $D / h$. Nevertheless, in this case overstocking is very high (because average deal purchase quantity for all values of $g \geq$ the average time between deals) ensuring that the average quantity on deal is still largest for the most peaked distribution.
} 
considers that optimal purchase policy encourages purchase of large quantities on deal only if deal savings exceed the excess holding cost that is incurred. This also suggests that a larger proportion purchased on deal should always be associated with a smaller average cost. Implications for Total cost are the same as implications for average cost since consumption rate is assumed to be constant per period.

3.3.2. Deal Frequency. Deal frequency in a time period $=$ time period $/($ mean time between deals). The mean time between deals is affected by dealing rate and delay. For Implication 2, we hold delay constant and increase dealing rate. In Implication 3, we vary delay (and separately hold either deal frequency or dealing rate constant, while varying the other).

IMPLICATION 2a. The higher the rate of dealing $(\lambda)$ (for the same shape and delay parameters), (i) the lower the average quantity purchased on deal, (ii) larger the probability of overstocking, ${ }^{10}$ (iii) larger the proportion purchased on deal, and (iv) lower the average cost .

With delay held constant, deal frequency increases as the rate of dealing in increased. It follows that consumers presented with more frequent deals should purchase a smaller quantity on deal (Figure 2). Consider Equations (2) and (3). Holding all else constant, the smaller $\sum_{i=0}^{K-1} q_{i}$ in equation (2) (i.e., the higher deal frequency), the smaller the optimal purchase quantity. This result is consistent with expected behavior for rational consumers, and has been implied by zero and first-order models (Golabi 1985, Kalymon 1971). Implication 2a generalizes the result to higher-order patterns.

Two forces act on the probability of overstocking. On the one hand, the higher the dealing rate, the more likely it is that a deal might occur while the consumer is holding inventory (i.e., the higher the dealing rate, the higher the probability of overstocking). On the other, to the extent that higher dealing rate implies smaller quantities purchased on deal, the probability of overstocking should decrease. Because the first effect is stronger, however, a higher dealing rate is associated with a higher probability of overstocking.

Further, the higher the dealing rate, the higher the proportion purchased on deal, and the lower the average cost.

IMPLICATION 2b. As dealing rate increases (for the same shape and delay parameters), holding cost first increases and then decreases.

If dealing rate is increased, while delay is held constant, deal frequency is also increased. As deal frequency increases and consumers purchase a larger proportion on deal, holding cost increases. However, since a higher deal frequency also results in a smaller average quantity purchased on deal, beyond a certain deal frequency, holding cost decreases. Holding cost thus exhibits a nonmonotonic relationship with deal frequency (and dealing rate).

In spite of the nonmonotonic relationship between holding cost and dealing rate, note that we still found a continuously negative relationship between average cost and dealing rate (Implication $2 \mathrm{a}$ (iv)). This occurs because as dealing rate increases, at first, consumers purchase larger quantities on deal (hence, increasing holding cost). However, deal savings more than outweigh the additional holding cost. Then, when dealing rate increases further so that deals are not rare any more and a smaller quantity is purchased on each deal (thus decreasing holding cost), the total proportion purchased on deal increases enough to decrease the average cost. Basically, with a higher dealing rate, average cost is lower, whether or not consumers have a higher holding cost. A higher quantity is only purchased on deal (i.e., a higher holding cost is only incurred) if it ensures a lower average cost for the consumer.

\footnotetext{
${ }^{10}$ Some discontinuities may accrue due to the discrete modelling procedure.
} 
3.3.3. Delay. Delay is the minimum interval between deals. Delay and dealing rate together determine deal frequency. If dealing rate $=\lambda$ and delay $=x$, then deal frequency $=($ number of weeks $) /(x+(1 / \lambda))$.

We examine two scenarios in which delay can vary. In scenario 1 (Implication 3a), dealing rate is held constant, and deal frequency is permitted to vary. In scenario 2 (Implication 3b), dealing rate is adjusted so that the same deal frequency is maintained.

IMPLICATION 3a (same dealing rate/different deal frequency). The larger the enforced delay between deals (given the same shape and dealing rate), (i) the larger the average quantity purchased on deal, (ii) smaller the probability of overstocking, (iii) lower the proportion purchased on deal, and (iv) larger the average cost .

With dealing rate held constant, deal frequency decreases as delay is increased. Consider two retailers with the same dealing rate (e.g., the probability of a deal occurring in any week $=0.5$ ), but different delays. Retailer $A$ has a delay of 0 (deals may occur in consecutive weeks), retailer $B$ a delay of 1 (deals must be at least one week apart). Retailer $B$ 's higher delay for the same dealing rate yields a lower deal frequency, which will lead to larger quantity purchased on deal. This is the case for the two distributions in Figure 2 with same shape $(g)$, but different delay $(w)$; a larger quantity is purchased on deal for the distribution with the larger delay.

Increasing delay should directly decrease probability of overstocking, but increasing average quantity (a result of increasing delay) should increase it. Because the first effect is stronger, the larger the delay, the lower the probability of overstocking. In fact, for patterns with a positive delay the probability of overstocking is often zero when deal probability is high. ${ }^{11}$ Also, since deal frequency is lower, proportion purchased on deal is lower and average cost is higher.

IMPLICATION 3b (same deal frequency/different dealing rate). The larger the enforced delay between deals (given the same shape, but with dealing rate adjusted to maintain the same deal frequency), (i) the larger the average quantity purchased on deal, (ii) smaller the probability of overstocking, (iii) larger the proportion purchased on deal, and (iv) lower the average cost.

Increasing delay while maintaining the same deal frequency necessitates a higher dealing rate. For example, a retailer who offers 12 deals in a year with a minimum of three weeks between deals will have a higher dealing rate than a retailer that offers 12 deals per year with a minimum of one week between deals.

In Figure 3, to maintain the same mean, when delay was increased, dealing rate was appropriately decreased. We can see in Figure 3 that increasing delay decreases probability of overstocking and increases average quantity purchased on deal. The larger the delay for the same deal frequency, the smaller the interval in which a deal can occur and the greater the certainty of when a deal will occur. The distribution is thus more "peaked" and yields the results for greater "peakedness," namely, lower probability of overstocking and higher average quantity purchased on deal. For the same deal frequency, the larger the quantity purchased on deal, the larger the proportion purchased on deal and holding cost, and lower the average cost .

\subsection{Discussion}

The model allows us to propose a number of implications, most of which could not be proposed by previous (zero and first-order) models. However, some of the implications are suggested by earlier literature for much more restricted scenarios. For example, As-

\footnotetext{
${ }^{11}$ If deal probability is high, $K$ is low. Also, the next deal cannot occur for $w+1$ periods. Hence, if $K \leq w$ +1 , the consumer has a 0 probability of overstocking.
} 
suncao and Meyer (1994) indicate that the optimal purchase quantity on deal will be higher the lower is the probability of consecutive deals. Implication 1 (ii) extends this result beyond the next period after a deal occurrence to the much richer context of exploring the effect of certainty in deal timing in its entirety, i.e., the effect of certainty of a deal occurring in all periods from the last deal till the next deal occurs. Similarly, both zero and first-order models have implied that the higher the rate of dealing, the lower should be the quantity purchased on deal (Golabi 1985, Kalymon 1971). This is consistent with Implication 2 a (ii), which extends the implication to the more general case of higher-order dealing patterns.

Implications from the proposed model also explore in detail the effect of dealing patterns on factors other than purchase quantity, such as probability of overstocking, proportion purchased on deal, average cost and holding cost. Many of these results are nonintuitive, for example, the relationship of holding cost with deal frequency is found to be interestingly non-monotonic. We also explore the effect of other aspects of dealing patterns. An interesting aspect of dealing that the proposed model uniquely explores is the effect of "delay" or the minimum time between consecutive deals. In fact, the model allows us to analyze the effect of delay separately from the effect of deal frequency so that we can consider the impact of delay both a) while holding the dealing rate constant (causing deal frequency to decrease as delay increases), and b) adjusting the dealing rate to hold deal frequency constant. The latter is especially appealing since it shows the explicit effect of delay on consumer purchase behavior (even though deal frequency is constant), and provides an explanation for observed retailer behavior of having a minimum time between deals.

The model is rich and, if applied in different sets of numerical simulations, may be used to generate many other implications exploring the effect of other factors on consumer purchase behavior. For example, if one systematically varies the value of the deal amount, one can explore the effect of higher discounts on probability of overstocking, average deal purchase quantity, etcetera.

The foregoing implications explore the normative effect on purchase behavior of certainty in deal timing, deal frequency, and minimum time between deals. We now test these implications in a laboratory experiment to see if consumers behave as the normative model predicts.

\section{A Laboratory-based Comparison of Actual Versus Normative Buyer Behavior}

Implications 1 and $3 b$ were tested in an interactive between-subjects experiment in which stimuli were presented via personal computers. ${ }^{12}$ Computer-simulated shopping experiments have been employed previously by researchers to study the effect of different price sequences on purchase behavior (Buyyukurt 1986, Kahn and Louie 1990, Krishna 1991, Meyer and Assuncao 1990). Experiments employing laboratory settings and scanner data (Simonson and Winer 1992) and using laboratory settings and real shopping trips (Burke et al. 1990) have produced similar results.

Eighty-eight graduate business students participated in the experiment as part of a course requirement. Subjects were assigned randomly to the experiment condition and worked independently. In order to have discernibly different dealing patterns within a limited time frame, we tested the implications in a frequent dealing scenario. A four (type of dealing pattern: regular, uniform, geometric, delayed-geometric) by two (deal discount: low of $\$ 0.30$ and high of $\$ 0.50$ ) full factorial design was employed. The first three patterns were used to test Implication 1 (i.e., regarding the effect of "certainty in deal timing"). There is greatest certainty in deal timing for regular, lower for uniform,

${ }^{12}$ Testing all the implications would have necessitated increasing the number of treatments eight-fold. 
and lowest for geometric dealing distributions. The latter two patterns were used to test Implication $3 b$ (regarding the effect of delay given constant deal frequency). There was a larger delay (minimum interval) between deals for delayed-geometric versus geometric deals. The descriptions of the four patterns are provided later.

\subsection{Procedure}

Subjects were instructed to make successive purchase decisions for 2 liter soda bottles over 24 simulated weeks. ${ }^{13}$ Consistent with the model's assumptions, buyers were told to assume that they would go to the store each week and choose whether or not to make a purchase and, if purchasing, what quantity to buy. Buyers were required to consume one unit of the product per week. Additionally, a holding fee of $\$ 0.10$ per unit, per week was imposed. A screen display indicated when soda was on deal and the price, similar to an on-sale tag in the supermarket. Deal price was $\$ 0.79$ for the high deal amount condition, $\$ 0.99$ for the low deal amount condition. Off-deal price was $\$ 1.29$ for both conditions. Subjects' were instructed to minimize the total cost of purchasing and holding soda.

Deals occurred, on average, once in three weeks for each dealing pattern. Consistent with the model simulation, buyers were provided with accurate knowledge of deals. Buyers in the regular deal manipulation were told that deals occur every three weeks, those in the uniform deal manipulation that they occur with equal probability in the second, third, or fourth week from the prior deal, ${ }^{14}$ and those in the geometric and delayedgeometric manipulations that there was a third and half chance, respectively, of a deal in any week irrespective of when the last deal occurred. In addition, subjects in the delayed-geometric manipulation were told that deals did not occur in consecutive weeks.

Pretests. We pretested with an independent sample whether consumers understood the different dealing patterns. Eight subjects for each treatment were provided with descriptions of dealing patterns and questioned about the probability of a deal occurring in specific future weeks given that a deal had/had not occurred in certain previous weeks. Twenty-nine of 32 subjects answered all questions correctly.

To determine whether subjects paid attention to holding cost, we engaged 12 additional subjects ( three for each dealing pattern) in the experiment who were not given a holding cost. Between these subjects and those who were given a holding cost, we found a substantial difference in deal purchase quantity $(p<0.01)$, suggesting that subjects did pay attention to holding cost and the objective function. The experiment took between five and 20 minutes for each subject. ${ }^{15}$

Manipulation checks. At the end of the experiment, subjects were asked to recall sale and regular prices. Recall was very accurate ( 83 of 88 subjects recalled both prices correctly) suggesting that subjects paid attention to the information that was provided. Subjects also had the option of being told what the experiment was designed to test. Eightytwo of the 88 subjects exercised the option, suggesting that they were interested in the task.

\subsection{Results}

Separate ANOVA were run with probability of overstocking, average deal purchase quantity, proportion of quantity purchased on deal, and average cost as dependent variables. For probability of overstocking and proportion purchased on deal we used log

\footnotetext{
${ }^{13}$ Subjects were not told for how many weeks they would be shopping to avoid potential end-game effects.

${ }^{14}$ It being easier to describe exactly regular and exactly uniform distributions, rather that a Weibull approximation of the same, this is what we did. The implications hold for these descriptions as well.

${ }^{15}$ Seventy-eight subjects took $>15$ minutes. Eighty five took $>10$ minutes.
} 
TABLE 1

Experiment Results for Implication 1

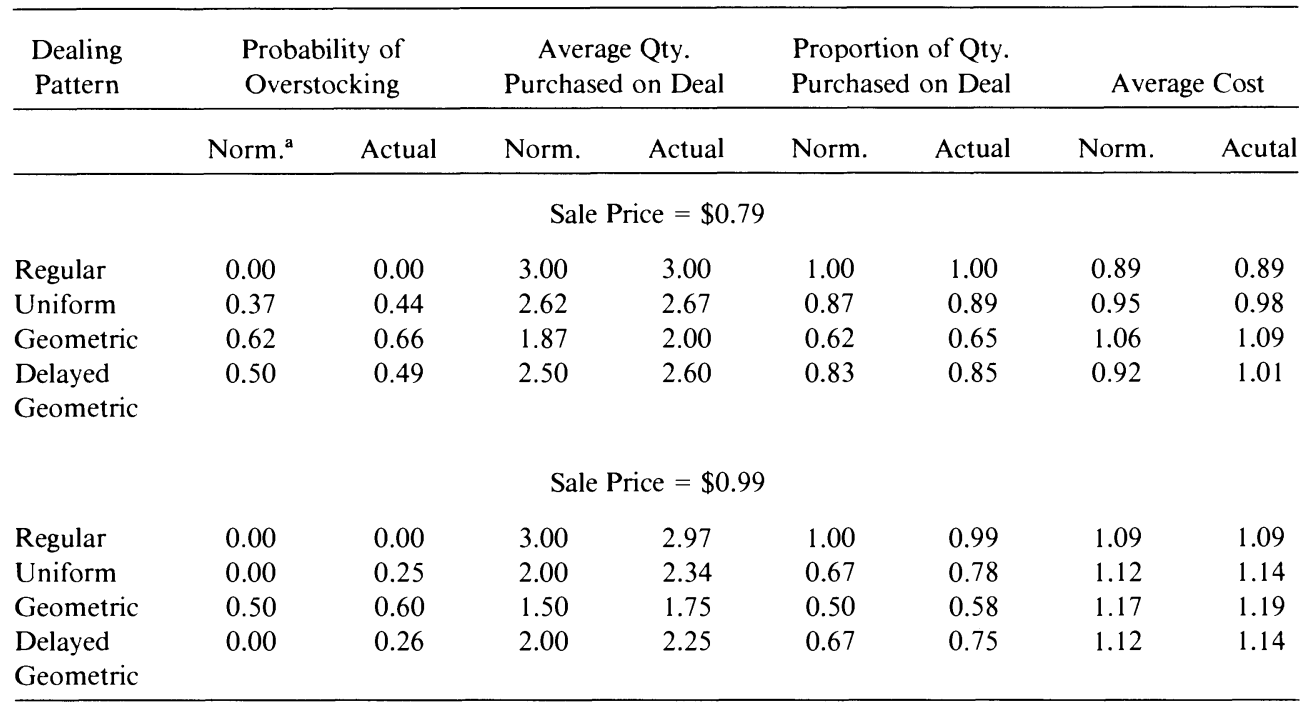

${ }^{a}$ Norm. denotes Normative

odds (i.e., $\ln (p /(1-p))$,) for the dependent variable. ${ }^{16}$ Independent variables for each ANOVA were dealing pattern and sale price and their interaction. Table 1 reports normative and actual results for each treatment. Normative values were computed separately for each dealing pattern by inserting the values of all parameters into the model.

Implication 1 (certainty in deal timing) - Table 2 reports the ANOVA results for the different dependent measures.

Implication 1 (i) - Probability of overstocking, as one might expect, was 0 for regular deals and greater than 0 (actually, $>0.3)$ for the other two patterns $(p<0.01) .{ }^{17}$ ANOVA with log-odds of the probability of overstocking as the dependent variable reveals a significant main effect for deal pattern $(F(2,60)=172.12, p<0.01)$. Sale price and its interaction with dealing pattern were not significant $(p>0.2$; see Table 2$)$. Probability of overstocking thus differed across dealing patterns, with overstocking more likely when the discount was larger. The model's prediction of a greater probability of overstocking for larger discounts ( compare normative values for probability of overstocking for regular, uniform and geometric patterns when sale price is $\$ 0.79$ versus $\$ 0.99$, in Table 1 ) was supported directionally, but not to a degree that was significant.

The relative probability of overstocking is consistent with that predicted for the different dealing patterns: regular $<$ uniform $<$ geometric (Table 1). A-priori planned comparisons reveal that log-odds of the probability of overstocking are significantly smaller $(p<0.05$; one-tailed Tukey test; minimum significant difference between means $($ MSD $)=1.4343$ ) when deals are regular versus uniform $(\bar{X}=0$ vs. $\bar{X}=0.35)$, and uniform versus geometric $(\bar{X}=0.35$ vs. $\bar{X}=0.63) .^{18}$

Implication 1 (ii) - For Average deal purchase quantity, ANOVA reveals significant main effects for deal pattern $(F(2,604)=172.0, p<0.01)$ and sale price $(F(1,60)=5.46$,

\footnotetext{
${ }^{16}$ In order to use log-odds, if probability of overstocking or proportion of quantity purchased on deal was 0 or 1 , we changed it to 0.00001 and 0.99999 respectively.

${ }^{17} T$-tests of difference from a standard.

${ }^{18}$ Note that these are means for the probability of overstocking, whereas the analysis is done on log odds of probability of overstocking.
} 
TABLE 2

ANOVA Results for Implication 1

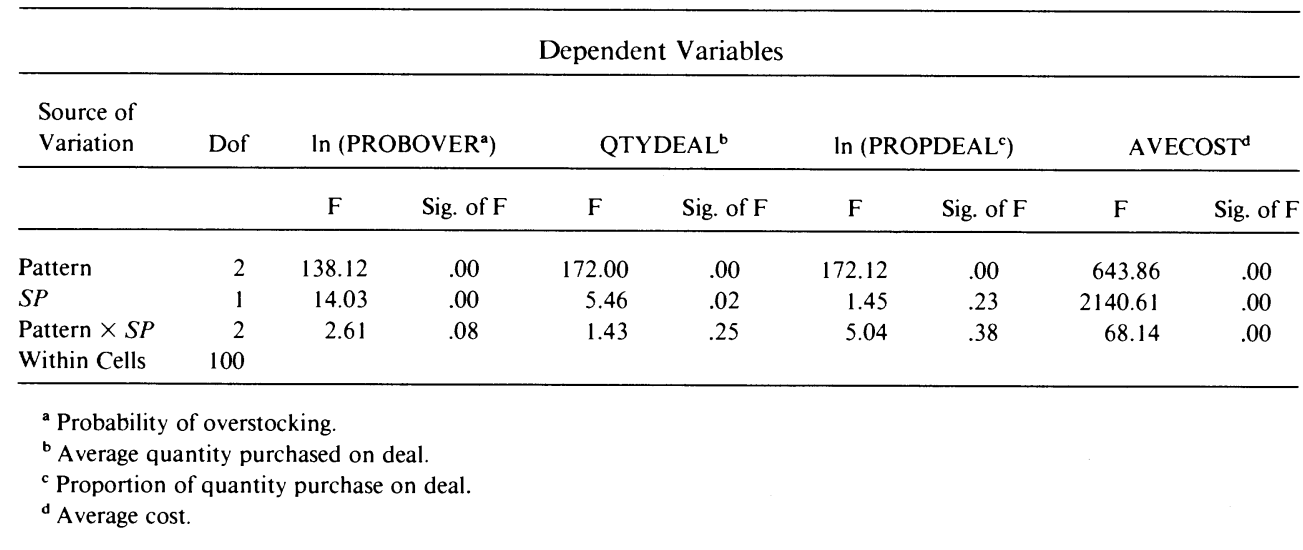

$p<0.05)$, but not for the interaction between the two ( $p>0.2$; see Table 2). Consumers thus purchased different quantities under different dealing patterns and bought larger quantities when the discount was higher, as predicted by the model. Relative purchase quantity for the different dealing patterns is also consistent with the model: regular $>$ uniform $>$ geometric ( see Table 1). A-priori planned comparisons reveal that purchase quantity is significantly smaller $(p<0.05$; one-tailed Tukey tests; MSD $=0.1399)$ when deals are regular versus uniform $(\bar{X}=2.983$ vs. $\bar{X}=2.506)$, and uniform versus geometric $(\bar{X}=2.506$ vs. $\bar{X}=1.875)$.

Implication 1 (iii) - Proportion of quantity purchased on deal, as one might expect, is nearly $1(=0.99)$ for regular deals and less than 1 (actually, $<0.85)$ for the other patterns $(p<0.01) .{ }^{19}$ Significant main effects were found for deal pattern $(F(2,60)$ $=138.12, p<0.01)$ and sale price $(F(1,60)=14.03, p<0.01)$. The interaction was also mildly significant $(F(2,60)=2.61, p<0.1)$. Consumers thus purchased different proportions on deal for different dealing patterns and purchased larger proportions for larger discounts.

Tukey tests $(p<0.05 ;$ MSD $=2.0516)$ reveal that a strong ordering of the proportion of quantity purchased on deal is significant for regular versus uniform $(\bar{X}=0.99$ vs. $\bar{X}$ $=0.84)$, and uniform versus geometric patterns $(\bar{X}=0.84 \text { vs. } \bar{X}=0.62)^{20}$ when sale price is $\$ 0.79$, but only for regular versus uniform patterns $(P<0.05 ; \mathrm{MS}=1.5686 ; \bar{X}$ $=10.64$ vs. $\bar{X}=1.40$ ) when sale price is $\$ 0.99$.

Implication 1 (iv) -For Average cost, ANOVA shows significant main effects for dealing pattern $(F(2,60)=643.86, p<0.01)$, sale price $(F(2,60)=2140.61, p<0.01)$, and the interaction between the two $(F(2,60)=68.14, p<0.01)$. Relative average cost for the different patterns is consistent with Implication $1(\mathrm{v})$ : regular $<$ uniform $<$ geometric.

Separate planned comparisons for the high discount $($ sale price $=\$ 0.79 ; \mathrm{MSD}=0.0127$ ) and low discount ( sale price $=\$ 0.99 ; \mathrm{MSD}=0.0121$ ) conditions reveal significant differences ( $p<0.05$; Tukey tests) between regular and uniform $(\bar{X}=0.89$ vs. $\bar{X}=0.98)$ and between uniform and geometric patterns $(\bar{X}=0.98$ vs. $\bar{X}=1.09)$ in the high discount condition. Lesser, but still significant, differences ( $p<0.05$; Tukey tests) between regular and uniform $(\bar{X}=1.09$ vs. $\bar{X}=1.14)$ and between uniform and geometric patterns $(\bar{X}$ $=1.14$ vs. $\bar{X}=1.19$ ) were observed in the low discount condition.

\footnotetext{
${ }^{19} T$-tests of difference from a standard.

${ }^{20}$ Note that these are means for the proportion of quantity purchased on deal, whereas the analysis is done on log odds of probability of overstocking.
} 
TABLE 3

ANOVA Results for Implication 2

\begin{tabular}{|c|c|c|c|c|c|c|c|c|c|}
\hline \multicolumn{10}{|c|}{ Dependent Variables } \\
\hline \multirow[t]{2}{*}{$\begin{array}{l}\text { Source of } \\
\text { Variation }\end{array}$} & \multirow[t]{2}{*}{ Dof } & \multicolumn{2}{|c|}{ In (PROBOVER $\left.{ }^{a}\right)$} & \multicolumn{2}{|c|}{ QTYDEAL $^{\mathbf{b}}$} & \multicolumn{2}{|c|}{$\ln \left(\right.$ PROPDEAL $\left.^{\mathrm{C}}\right)$} & \multicolumn{2}{|c|}{ AvECOST ${ }^{d}$} \\
\hline & & $\mathrm{F}$ & Sig. of $F$ & $\mathrm{~F}$ & Sig. of $F$ & $\mathrm{~F}$ & Sig. of $F$ & $\mathrm{~F}$ & Sig. of $F$ \\
\hline Pattern & 1 & 5.57 & .02 & 6.90 & .01 & 7.69 & .00 & 29.96 & .00 \\
\hline$S P$ & 1 & 1.70 & .20 & 11.13 & .00 & 11.23 & .00 & 205.44 & .00 \\
\hline Pattern $\times S P$ & 1 & 0.73 & .40 & 1.13 & .29 & 2.19 & .15 & 1.30 & .26 \\
\hline Within Cells & 100 & & & & & & & & \\
\hline
\end{tabular}

a Probability of overstocking.

${ }^{b}$ Average quantity purchased on deal.

${ }^{\mathrm{c}}$ Proportion of quantity purchase on deal.

${ }^{\mathrm{d}}$ Average cost.

Implication 3b (delay, holding deal frequency constant) - Table 3 reports the ANOVA results for the different dependent measures. ${ }^{21}$

Implication 3b (i)-For Probability of overstocking, we observed a significant main effect for deal pattern $(F(1,40)=5.57, p<0.05)$. Sale price and the interaction between dealing pattern and sale price were not significant ( $p>0.1$; see Table 3$)$, indicating that probability of overstocking differed for delayed-geometric and geometric dealing patterns, but consumers were not more likely to overstock when the discount was larger. The model's prediction of a larger probability of overstocking for larger discounts ( compare normative values for probability of overstocking for geometric and delayed-geometric patterns when sale price is $\$ 0.79$ versus $\$ 0.99$, in Table 1 ) was supported directionally, but not at a level that was significant. Relative probability of overstocking for the different dealing patterns is consistent with the model's prediction: delayed-geometric < geometric (see Table 2).

Implication 3b (ii) -For Average deal purchase quantity, we found significant main effects for deal pattern $(F(1,40)=6.90, p<0.05)$ and sale price $(F(1,40)=11.13, p$ $<0.01)$, but not for the interaction between the two $(p>0.2$; Table 3$)$. As expected, consumers purchased different quantities under delayed-geometric and geometric dealing patterns and bought larger quantities when the discount was higher. Relative purchase quantity for the different dealing patterns is consistent with the model's prediction: delayed-geometric $>$ geometric ( see Table 1).

Implication 3b (iii)-For Proportion of quantity purchased on deal, ANOVA reveals significant main effects for deal pattern $(F(1,40)=7.69, p<0.01)$ and sale price $(F(1,40)$ $=11.23, p<0.01)$. The interaction is not significant $(p>0.1$; Table 3$)$. Consumers thus purchased larger proportions of the product on deal when discounts were larger (Table 1) and bought larger proportions on deal for delayed-geometric versus geometric dealing patterns.

Implication 3b (iv)-For Average cost, ANOVA reveals significant main effects for dealing pattern $(F(1,40)=29.96, p<0.01)$ and sale price $(F(1,40)=205.44, p<0.01)$, but the interaction between the two was not significant $(p>0.2)$. Relative average cost for the different patterns is consistent with the model's prediction: delayed-geometric $<$ geometric (see Table 2).

${ }^{21}$ For Implication 3b, we tested only geometric versus delayed-geometric patterns. Including delayed-regular and delayed-uniform would have increased the number of treatments. Also, for both exactly regular and exactly uniform distributions (versus a Weibull approximation of the same), one cannot really distinguish between delay and rate. 


\subsection{Deviations and Consistency in Actual Versus Normative Behavior}

We found certain types of buyer behavior to be consistent with model implications and some systematic differences between normative and actual behavior. The main result demonstrating rationality in consumer decision-making is that consumers behave differently if deal patterns vary, even if deal frequency is the same. Consistent with model predictions, quantity purchased on deal, and proportion of quantity purchased on deal are higher when there is greater certainty in deal timing. They are thus highest for regular deals, lower for uniform deals, and lowest for geometric deals. Probability of overstocking and average cost follow the opposite ordering. In fact, probability of overstocking is nearly zero when deals are regular, greater than zero otherwise. Consumers purchase from deal to deal when deals are regular, but not for the other dealing patterns.

Average quantity purchased on deal is larger when there is a larger minimum interval between deals. It is thus larger if deals are not allowed to occur in consecutive weeks (delayed-geometric pattern) than if they are allowed to occur in consecutive weeks (geometric pattern), even if deal frequency is the same. Also, consistent with the model's predictions: probability of overstocking is smaller; proportion purchased on deal is larger; and average cost is lower in the delayed-geometric versus geometric patterns.

Among systematic biases revealed in buyer behavior, consumers have a tendency to overbuy on deal. For nonregular dealing treatments, actual purchase quantity and actual proportion purchased on deal were larger than optimal, suggesting that consumers did not pay enough attention to holding cost. It may be that consumers pay more attention to holding cost in real life, in which case the bias of overbuying may not be observed. With the purchase of larger than optimal quantities on deal, probability of overstocking became excessive.

Some of the consumers did not respond to every deal as the normative model would predict, suggesting, in contrast, that consumers paid too much attention to holding costs. However, this result may be obtained if consumers do not purchase on deal if their stock is above a certain level. Also, given that consumers buy larger than optimal quantities on deal, it may actually not be optimal to purchase on every deal. Thus, consumers may buy a lot, when they do make a deal purchase, but may not respond to a deal if they have a large stock.

Overall, our results seem to indicate that consumers are extremely good forward planners. As to the real-world validity of these experimental results, one would expect consumers to act according to model predictions if they follow two simple rules, (1) if there is a possibility of another deal occurring soon, consumers should purchase less on the present deal, and (2) consumers with larger inventory in stock should purchase smaller quantities on deal ( since timing of deal occurrence varies across different dealing patterns, one would expect consumers' inventory at the time of a deal to also vary across dealing patterns). Consumer behavior that conforms to these two rules will generally be consistent with the model's predictions.

\section{Implications for Retailers and Summary}

Among retailers' many reasons for offering deals, one oft-cited objective is to pass inventory holding cost on to consumers (Blattberg et al. 1981). As a theoretical comment, we suggest that an increase in consumer holding cost does not necessarily correspond to a decrease in retailer holding cost. An inefficient consumer who maintains $x$ units in stock, for example, would incur a holding cost of $x$ units per period, but would not reduce the retailer's holding cost by $x$ units per period. Retailers benefit from the amount consumers "purchase" on deal, which translates into a direct transfer of inventory. 
"When" this transfer takes place is also significant since a deal pattern in which deals occur earlier enable a retailer to pass on inventory sooner and thereby lower holding costs.

We consider first the amount of inventory transferred on deal. Assuming that consumers make a purchase on each deal and the number of deals is the same across dealing patterns, if the average amount purchased on deal is larger, the total quantity purchased on deal is also larger, and the retailer transfers more inventory. If mean time between deals is the same across dealing patterns, the effect of when the transfer of inventory takes place is not large. Specifically, deals may occur closer together in geometric and uniform patterns than in the regular case, but they may also occur further apart. If mean time between deals is thus constant, maximum transfer of inventory should occur when the largest average quantity is purchased on deal, which happens with the most peaked distribution (regular dealing; Implication 1(ii)).

From Implication $3 \mathrm{~b}$ it appears that spacing deals apart should encourage consumers to purchase larger quantities on deal, even if the total number of deals is the same. Hence, if the objective of the retailer is to sell the maximum amount on deal (for purposes of transferring inventory, or if the margins on deal are higher), this suggests a reason why retailers may be following the current policy of not having deals in consecutive weeks or too close together (Curhan and Kopp 1986).

Our main objective was to provide a framework for understanding how dealing patterns may affect consumer purchase behavior. We developed a model that shows normative purchase behavior to vary for different dealing patterns in ways that cannot be predicted by zero-order or first-order models. The former cannot discriminate between two dealing patterns that have the same mean (same deal frequency); the latter cannot incorporate many aspects of dealing patterns. For example, they cannot incorporate certainty in dealing and therefore cannot distinguish among patterns in which deals occur regularly (e.g., every $n$ weeks), slightly less regularly (e.g., every $n-1, n, n+1$ weeks with equal chance), and much less regularly (e.g., every $n-3$ to $n+3$ weeks with equal chance). Also, they cannot incorporate spacing between deals and thus cannot distinguish between two patterns, where one has a minimum time interval of two weeks between deals, whereas the other has four.

The model demonstrates how any dealing pattern may be incorporated into normative purchase quantity models. The model structure proposed here can be used to construct other purchase policy models (e.g., retailer ordering models) that incorporate dealing patterns.

Although consumers' purchase decisions may not correspond precisely to the model's precisely, laboratory tests suggest that consumer behavior, by and large, is consistent with implications of the model. The model thus represents a good first approximation of consumer purchase behavior useful for analyzing the effect of dealing patterns on such behavior.

Scanner data-based research offers further empirical support for the model. The model's implication that optimal purchase quantity is a decreasing function of deal frequency and holding cost, and an increasing function of deal amount, is consistent with research that has shown that brands with higher deal frequency obtain a smaller market share gain on deal than brands with a lower deal frequency (Gurumurthy and Little 1987). Also, Raju (1992) found across 27 product categories that an increase in the frequency of discounts decreases variability in category sales, implying that lower quantities would be purchased on deal versus off-deal when deal frequency is higher. It has also been shown that goods that are easier to stock-up (i.e., that have lower holding costs) have greater price-elasticities than goods that are more difficult to stock-up (Litvack, Calantone and Warshaw 1985). That higher discounts lead to greater purchase quantities has been 
demonstrated repeatedly (Gupta 1988, Krishnamurthy, Lakshman and Raj, 1988, Neslin, Henderson and Quelch 1985, Raju 1992).

\section{Limitations and Extensions}

We made a number of assumptions in this paper that are common to this stream of literature. It is important to consider how they affect our model predictions. Our assumption, for example that consumption per week is an integer multiple of available package-sizes may be valid in product categories in which goods are available in many different package sizes or even if they are available in one small package-size (e.g., tuna, catfood, yogurt, soft drinks, most snack foods, orange juice, milk). But to the extent that it may not be valid in other product categories, it represents a limitation of the model. It may not be possible, for example, to purchase optimal quantities of a product that is offered in a single large package-size. Moreover, the likelihood that they are holding a large inventory of such a product might preclude consumers from responding to deals that occur close together. This would accentuate differences in purchase behavior across different dealing patterns. Consumers facing less peaked dealing distributions might be less likely to respond to a deal than consumers who face regular deals. We also assume that consumption rate is constant. We could make consumption a function of price and current inventory as Assuncao and Meyer (1991) have done and modify our model accordingly.

We assume there to be no cost of shopping for the product class; if there is, consumers with higher inventory would be less likely to respond to a deal. Again, this would exaggerate differences in purchase behavior across dealing patterns. We also assume a linear holding cost. Even if holding costs were convex, all dealing patterns should be affected similarly. We would expect optimal deal purchase quantity to decrease, but we would not expect the model implications to change.

We consider only the case of a single good. The model can be extended to the multiple brand case along the lines illustrated by Krishna (1992), but doing so will render any normative analysis much more complex since deal timing and amounts for multiple brands will now affect consumer purchase behavior.

A further limitation is the little supporting data we can draw upon. Nevertheless, the difficulty of doing real-world descriptive studies of the effect of dealing patterns on consumer purchase behavior makes the little light our model sheds on the subject seem that much brighter. We suggested earlier that conformance to two simple rules would render consumer behavior consistent with that predicted by our model: given the possibility of a deal occurring soon, consumers should be expected to purchase less on deal, and if they are holding a larger inventory to purchase smaller quantities.

We leave to future research to determine optimal purchasing and pricing policies for retailers presented with different dealing patterns by manufacturers. One approach might be to construct a model similar to the one developed here that accommodates changes in retailer sales (similar to the proposed model's changes in consumption rate) as a function of retailer price.

Research might also be undertaken to discover optimal promotion policies for manufacturers and retailers when consumers are aware of dealing patterns and take them into account in their purchase decisions. Several models for determining optimal promotion policies for manufacturers have established as the equilibrium condition regular (Lal 1990, Lattin 1991) or random dealing (Varian 1980, Narasimhan 1988, Raju, Srinivasan and Lal 1990). But they do not consider the effect of consumer expectations of these same dealing patterns on consumer purchase behavior. These models could be extended to do so. Similarly, models built to support retailer pricing decisions (e.g., 
Armstrong, Bass and Rao 1992) do not incorporate the effect of different retailer pricing patterns on consumer purchase behavior.

In conclusion, our research suggests that consumer recognition of dealing patterns can significantly influence their consumer purchase behavior. This should be taken into account by models that incorporate consumer response to price promotions. ${ }^{22}$

Acknowledgements. This paper has benefitted immensely from comments by Joao Assuncao, Imran Currim, Sunil Gupta, Bari Harlam, Rajeev Kohli, Don Lehmann, Bob Meyer, Ambar Rao, Paul Zipkin, the Area Editor and two anonymous reviewers. I especially want to thank Praveen Kopalle for his help in running the laboratory experiment.

${ }^{22}$ This paper was received April 28, 1992, and has been with the author 10 months for 4 revisions. Processed by Scott A. Neslin, Area Editor.

\section{Appendix}

A.1. LEMma 1. The optimum policy will be to buy up to $K$ periods on deal for some $K \geq 0$.

Follow a FIFO accounting method (which method you follow should make no difference to the total cost $V_{m}(\cdots)$ obtained for any $m$ ), and tag each unit purchased for the period in which it is to be consumed.

Let $M_{i+1, j}=$ minimum expected ordering and holding cost for 1 unit in periods $i+1, i+2, \ldots, j$ for consumption in period $j$, and $N_{i, j}=$ cost of buying in period $i$ and holding up until period $j$ for consumption in period $j$.

$M_{i, j+1} \leq M_{i, j}+\alpha^{j} h$ since we can always buy the unit for consumption in period $j+1$ as if it were required for period $j$ and then hold it for 1 period.

Clearly, $N_{i, j+1}=N_{i, j}+\alpha^{j} h, \alpha^{j} h$ being the discounted holding cost for the additional period

$$
\Rightarrow M_{i, j+1}-N_{i, j+1} \leq M_{i, j}-N_{i, j} .
$$

One should buy in period $i$ for consumption in period $j$ if $N_{i j}<M_{i+1, j}$ and only if $N_{i, j} \leq M_{i+1, j}$. That is, one should purchase in period $i$ for consumption in period $j$ if the price of buying in period $i$ and holding till period $j$ is lower than the minimum expected cost of buying from period $i+1$ onwards and holding till period $j$. Thus the optimum policy dictates purchasing for a whole period.

If $N_{i j}=M_{i+1 . j}$ we could purchase for the whole period $j$, none of it, or some fraction. Then the minimum expected cost of consumption in period $i$ is still the same for all three choices. We may as well choose either to buy $c$ units for period $j$ or none at all.

We have thus shown that one should always buy to bring the inventory up to an integral number of periods. QED

\section{A.2. Minimizing $V_{m}(\alpha, z)$}

We first propose Lemma 2 which aids in minimizing $V_{m}(\alpha, z)$.

LEMMA 2. Irrespective of the choice of $K$,

$$
V_{m}(\alpha, z)=V_{m}(\alpha, 0)-S z .
$$

This lemma implies that the total cost when the buyer begin with inventory $z$ equals the total cost when the buyer begins with inventory 0 , minus the cost of purchasing $z$ units on deal. The lemma follows directly from the Expected Total Cost Equation (equation (1) in the text). Observe in equation (1) that there is only one term on the RHS where $z$ occurs. Also, remember that $V_{m}(\alpha, z)$ is measured at a time at which a deal occurs, and $z$ is the inventory with the consumer before he makes a purchase.

Due to stationarity of the dealing process, and because of an infinite time horizon, $V_{m}(\alpha, z)$ is the same for all $i$. Therefore, $V_{m}(\alpha, z)$ may just be denoted by $V(\alpha, z)$.

Using Lemma 2 and stationarity, it follows from equation (1), that

$$
\begin{aligned}
V(\alpha, 0)= & S K c+h c(K-1)+\alpha\left[q_{1}(K-2) h c+p_{1} V(\alpha, 0)-p_{1} S(K c-c)\right] \\
& +\alpha^{2}\left[q_{2}(K-3) h c+p_{2} V(\alpha, 0)-p_{2} S(K c-2 c)\right]+\cdots+\alpha^{K}\left[q_{K} R c+p_{K} V(\alpha, 0)\right] \\
& +\alpha^{K+1}\left[q_{K+1} R c+p_{K} V(\alpha, 0)\right]+\cdots \\
\Leftrightarrow & V(\alpha, 0)=S K+h c \sum_{i=0}^{K-1} \alpha^{i}(K-1-i) q_{i}+R c \sum_{i=k}^{\infty} \alpha^{i} q_{i}
\end{aligned}
$$




$$
\begin{aligned}
&+V(\alpha, 0)\left(\sum_{i=1}^{\infty} \alpha^{i} p_{i}\right)-S \sum_{i=1}^{K}(K c-i c) \alpha^{i} p_{i} \\
& \Leftrightarrow V(\alpha, 0)\left(1-\sum_{i=1}^{\infty} \alpha^{i} p_{i}\right)= S K c+h c \sum_{i=0}^{K-1} \alpha^{i}(K-1-i) q_{i} \\
&+R c \sum_{i=K}^{\infty} \alpha^{i} q_{i}-S \sum_{i=1}^{K}(K c-i c) \alpha^{i} p_{i} .
\end{aligned}
$$

Since $\sum p_{i}=1$, and discount rate $\alpha<1, \sum_{i=1}^{\alpha} \alpha^{i} p_{i}<1$. Therefore, to minimize $V(\alpha, 0)$, we need to minimize the RHS of equation (A.1). Thus we need to minimize:

$$
O(K)=S K c+h c \sum_{i=0}^{K-1} \alpha^{i}(K-1-i) q_{i}+R c \sum_{i=K}^{\infty} \alpha^{i} q_{i}-S \sum_{i=1}^{K}(K c-i c) \alpha^{i} p_{i}
$$

Since we are dealing with discrete terms, we minimize by taking finite differences.

$$
\begin{gathered}
O(K)-O(K-1)=c\left[S+h \sum_{i=0}^{K-2} \alpha^{i} q_{i}-R \alpha^{K-1} q_{K-1}-S \sum_{i=1}^{K-1} \alpha^{i} p_{i}\right] \leq 0, \\
O(K+1)-O(K)=c\left[S+h \sum_{i=0}^{K-1} \alpha^{i} q_{i}-R \alpha^{K} q_{K}-S \sum_{i=1}^{K} \alpha^{i} p_{i}\right] \geq 0 .
\end{gathered}
$$

Letting $\alpha \rightarrow 1$ (A value of $\alpha$ close to 1 is quite realistic. Since total cost is discounted in each period, an $\alpha$ of 0.998 per period (per week) gives a discount rate of approximately $10 \%$ a year, a reasonable interest rate),

$$
O(K+1)-O(K)=c\left[S+h \sum_{i=0}^{K-1} q_{i}-R q_{K}-S \sum_{i=1}^{K} p_{i}\right] \geq 0=c\left[h \sum_{i=0}^{K-1} q_{i}-R q_{K}+S\left[1-\sum_{i=1}^{K} p_{i}\right]\right] \geq 0 .
$$

Since $q_{K}=1-\sum_{i=1}^{K} p_{i}$,

$$
\begin{gathered}
O(K+1)-O(K)=c\left[h \sum_{i=0}^{K-1} q_{i}-(R-S) q_{K}\right] \geq 0 \quad \text { and } \\
O(K)-O(K-1)=c\left[h \sum_{i=0}^{K-2} q_{i}-(R-S) q_{K-1}\right] \leq 0 .
\end{gathered}
$$

Therefore, the optimal $K$ is such that,

$$
\frac{D}{h} q_{K} \leq \sum_{i=0}^{K-1} q_{i} \quad \text { and } \quad \frac{D}{h} q_{K-1} \geq \sum_{i=0}^{K-2} q_{i}
$$

To show that a minimum exists for $O(K)$, we need to show that only one $K$ satisfies the inequalities above. We know that $q_{i}$ is monotonically nonincreasing in $i$. Therefore, the LHS of the inequalities is monotonically non-increasing for larger $K$. The RHS is monotonically nondecreasing in $i$. Hence, there will be one unique crossing, and therefore only one value of $K$ to satisfy the crossing point of the functions given by the inequalities.

\section{A.3. Estimating Optimal K for a Discretized Weibull Distribution}

The c.d.f. for a Weibull is $F(x)=1-\exp \left[-(\lambda(x-w))^{g}\right]$. To discretize the Weibull, $p_{t}=F(t)-F(t-1)$. This implies that

$$
p^{t}=-\exp \left[(\lambda(t-w))^{g}\right]+\exp \left[-(\lambda(t-1-w))^{g}\right] .
$$

Therefore, $\sum_{j=1}^{i} p_{j}=1-\exp \left[-(\lambda(1-w))^{g}\right]$ provided $t>w$ and $q_{i}=\exp \left[-(\lambda(1-w))^{g}\right]$.

We now derive the optimal $K$ by using equations (2) and (3) of the text.

\section{References}

Armstrong, Marcia K., Frank M. Bass, and Ram C. Rao (1992), "The Normative Impact of Trade Promotion on Forward Buying and Retail Promotion," Working Paper, Washington University, St. Louis.

Assuncao, Joao and Robert J. Meyer (1993), "The Rational Effect of Price Uncertainty on Sales-Price Relationships," Management Science, 39 (May), 517-535.

Bellman, Richard (1957), "Dynamic Programming," Princeton, NJ: Princeton University Press. 
Blattberg, R., Eppen, G., and Lieberman, J. (1981), “A Theoretical and Empirical Investigation of Price Deals for Consumer Durables,” Journal of Marketing, 45 (Winter), 116-129.

Burke, Raymond R., Bari Harlam, Barbara Kahn, and Leonard M. Lodish (1992), "Purchase Time Compression Study: A Comparison of Laboratory Purchasing with Actual Purchase Behavior," Journal of Consumer Research, 19 (June), 71-82.

Buyukkurt, B. Kemal ( 1986), "Integration of Serially Sampled Price Information: Modelling and Some Findings," Journal of Consumer Research, 13 (December), 357-373.

Curhan, Ronald C. and Robert J. Kopp (1986), "Factors Influencing Grocery Retailers' Support of Trade Promotions," Report No. 86-104. Cambridge, MA: Marketing Science Institute, July.

Dickson, Peter R. and Alan G. Sawyer (1990), "The Price Knowledge and Search of Supermarket Shoppers," Journal of Marketing, July, 54 (3), 42-53.

Golabi, Kamal (1985), “Optimal Inventory Policies When Ordering Prices Are Geometric," Operations Research, 33 (3), 575-588.

Gupta, Sunil (1988), "Impact of Sales Promotions on When What, and How Much to Buy, Journal of Consumer Research, 25 (November), 342-355.

Gurumurthy, Kalyanaram and John D. C. Little (1987), "A Pricing Model Based on Perception Theories and Its Testing on Scanner Panel Data," Working Paper, Massachusetts Institute of Technology, Cambridge, MA.

Helsen, Kristiaan and David Schmittlein (1992), "Some Characterizations of Stockpiling Behavior Under Uncertainty," Marketing Letters, 3 (1), 5-16.

Kahn, Barbara E. and Therese A. Louie (1990), "Effects of Retraction of Price Promotions on Brand Choice Behavior for Variety-Seeking and Last-Purchase-Loyal Consumers," Journal of Marketing Research, 27 (August), 279-289.

— and David C. Schmittlein (1989), "Shopping Trip Behavior," Marketing Letters, 1 (1), 55-70.

Kalymon, Basil A. (1970), "Stochastic Processes in a Single-Item Inventory Purchasing Model," Operations Research, 19, 1434-1458.

Krishna, Aradhna (1991), "The Effect of Dealing Patterns on Consumer Perceptions of Deal Frequency and Willingness to Pay," Journal of Marketing Research, 28 (November), 441-451.

(1992), "Modelling the Impact of Consumer Price Expectations for Multiple Brands on Consumer Purchase Behavior," Marketing Science, 11 (Summer), 266-286.

- Imran C. Currim, and Robert W. Shoemaker (1991), "Consumer Perceptions of Promotional Activity," Journal of Marketing, 55 (April), 4-16.

Krishnamurthy, Lakshman and S. P. Raj (1988), "A Model of Brand Choice and Purchase Quantity Price Sensitivities," Marketing Science, 7 (Winter), 1-20.

Lal, Rajiv ( 1990), "Price Promotions: Limiting Competitive Encroachment," Marketing Science, 9 (Summer), 247-262.

Lattin, James M. ( 1991), "Making Explicit The Role of The Retailer in Explaining Manufacturer Trade Deals," Working Paper, Stanford University, Stanford, CA.

Le Boutillier, John, Susanna Shore Le Boutillier, and Scott A. Neslin (1994), "A Replication and Extension of the Dickson and Sawyer Price-Awareness Study," Marketing Letters, 5 (January), 31-42.

Litvack, David S., Roger J. Calantone, and Paul R. Warshaw (1985), "An Examination of Short-Term Retail Grocery Price Effects," Journal of Retailing, 61 (Fall), 9-25.

McCann, John, Ali Tadlaoui, and John Gallagher (1990), "Knowledge Systems in Merchandising: Advertising Design," Journal of Retailing, 66 (3), 257-277.

Meyer, Robert J. ( 1991 ), "Heuristics and Biases in Consumer Sequential Decision Making: Toward a Positive Theory of Intuitive Planning," Working Paper, University of Pennsylvania, Philadelphia, PA. and Assuncao, J. (1990), "The Optimality of Consumer Stockpiling Policies," Marketing Science, 9 (Winter), 18-41.

Narasimhan, Chakravarthi (1988), "Competitive Promotion Strategies," Journal of Business, 61 (4), 427449.

Neslin, Scott A., Caroline Henderson, and John Quelch (1985), "Consumer Promotions and the Acceleration of Product Purchases," Marketing Science, 4 (Spring), 147-165.

Raju, Jagmohan S. (1992), "The Effect of Price Promotions in Variability in Product Category Sales," Marketing Science, 11 (Summer), 207-220.

_ , V. Srinivasan, and Rajiv Lal (1990), "The Effects of Brand Loyalty on Competitive Price Promotion Strategy," Management Science, 36 (3), 276-304.

Simonson, Itamar and Russell S. Winer (1992), "The Influence of Purchase Quantity and Display Format on Consumer Preference for Variety," Journal of Consumer Research, 19 (June), 133-138.

Varian, H. (1980), “A Model of Sales," American Economic Review, 70 (September), 651-659.

Winer, Russell S. (1986), "A Reference Price Model of Brand Choice for Frequently Purchased Products," Journal of Consumer Research, 13 (September), 250-256. 